\title{
Construção de séries e micro-análise: notas sobre o tratamento de fontes para a história social
}

Luís Augusto Farinatti*

R esumo: N esteartigo, realiza-se uma reflexão acerca do tratamento de fontes em história social. 0 foco recai sobre as fontes que podem ser abordadas a partir de dois tipos de metodologias. De um lado, a construção de séries, com base em dados quantitativos eanônimos. D e outro, a micro-análise com vistas a reconstruir trajetórias e relações sociais a partir dos nomes dos agentes estudados. Tendo por base uma experiência de pesquisa, realizam-se reflexões sobre as possibilidades de investigação ensejadas por essas fontes, a compatibilidade de ambas as metodologias ea pertinência de sua utilização.

Palavras-chave: Fontes históricas. H istória social. H istória serial. M icro-história.

I ntrodução

A propostadesteartigo érefletir sobreo tratamento metodológico de um tipo específico de documento na pesquisa em história social. Trata-se dos documentos que permitem a elaboração de séries - por seu caráter massivo, homogêneo e reiterativo - mas que, ao mesmo

* D outor em H istória Social pelaUFRJ. Professor do Curso de H istória daU N IFRARS. E-mail: lafarinatti@ gmail.com 
tempo, podem ensejar análises de tipo relacional e micro-histórica, partindo da reconstrução de trajetórias individuais através de uma classificação nominal dos atores estudados. 0 que segue não tem a pretensão de se constituir em uma reflexão teórico-metodológica profunda, que exigiria um grau mais elevado de erudição e rigor

$\infty$ lógico. Trata-se, muito mais, do relato de uma experiência de pes-
\& quisa e das reflexões, dúvidas e soluções metodológicas que fui encontrando ao longo do trabalho com aquele tipo de documento, bem como de suas implicações teóricas.

\section{Recortar, medir, categorizar: a sociedade em números}

Como é do conhecimento de todos, um dos espaços de pesquisa em que a construção de séries estatísticas ganhou maior expressão e, sobretudo, no qual sua aplicação se ligou a um tipo de investigação que se propunha a não ser apenas econômica, mas também social, foi entre os historiadores franceses ligados ao grupo dos A nnales. Tratava-se de tomar fontes que fossem massivas (ou seja, que abarcassem uma parcela alargada do meio social estudado), reiterativas (que se repetissem no tempo por, no mínimo, algumas décadas) e homogêneas (que possuíssem o mesmo tipo de informação) e, a partir das informações dali retiradas, construir séries de dados que permitissem verificar sua variação no tempo e indagar sobre as razões dessa variação.

A orientação teórica assentava-se sobre uma visão restrita acerca das possibilidades de ação dos sujeitos históricos, expressa na fuga ao singular e ao episódico, bem como na busca das estruturas profundas da sociedade e da economia. $A$ atenção recaía sobre os movimentos conjunturais e sobre os grupos sociais recortados pela riqueza, pela condição jurídica ou pela profissão. E sses grupos eram abordados anonimamente. Ali estava uma tradição que se estendia desde E rnest Labrousse até a explosão das chamadas "monografias regionais francesas", sobretudo na década de 1960, 
com destaque para os trabalhos clássicos dePierre G oubert, E manuel Le Roy Ladurie, entre outros (LABRO USSE, 1962; G OUBERT, 1968; LADURIE, 1966).

No que se refere à historiografia brasileira, pode-se tomar como exemplo a importância da metodologia serial na produção em história agrária desde a década de 1980. A inda que a história agrária tenha sido vista quase como um sinônimo de história serial, cabe lembrar que aqui não se deve confundir o aporte metodológico com o campo de estudos: a abordagem serial foi empregada também em outros campos, como a história da família, trazendo grandes avanços. Já a história agrária, sobretudo nos últimos tempos, tem visto aumentar o número de trabalhos feitos a partir de metodologias diversas. É o caso, por exemplo, de importantes estudos sobre as práticas e conflitos gerados em torno do acesso à terra.

Voltemos, agora, aos estudos que se valeram, em alguma medida, de uma abordagem serial e, o que mais importa aqui, das fontes que empregaram. Para a história agrária, têm sido especialmente úteis as escrituras públicas, doações de sesmarias, processos de medição de terras, ações de despejo, censos agrários e, sobretudo, inventários post mortem. E stas últimas foram as fontes tomadas com mais freqüência por esses estudos, principalmente quando se valiam da seriação. Para o caso da história agrária, com forte acento nos aspectos econômicos, tal como foi praticada no Brasil na década de 1980, as peças dos inventários que mais chamaram a atenção dos historiadores foram as declarações e avaliações de bens e de dívidas ativas e passivas. A li deveriam estar listados todos os bens do inventariado (ainda que nem sempre isso ocorresse), aos quais eram atribuídos valores monetários pelos avaliadores, nomeados pela autoridade judiciária (FRAG OSO e PITZER, 1988). O s estudos se centraram na análise da composição do patrimônio produtivo, do percentual de dívidas e do montante de fortuna ali registrados. Trabalhos a partir dessa abordagem surgiram com força no Rio de Janeiro, em fins da década de 1970, através de pesquisadores nucleados em torno de M aria Yedda L inhares e Ciro Flamarion Cardoso. M as 
também se espalharam, através de diferentes redes de pesquisadores, por diversas regiões do Brasil - na Bahia, em São Paulo, em Minas G erais, no Paraná e no Rio G rande do Sul, entre outros

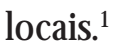

N esse contexto, houve significativos avanços no conhecimento da realidade socioeconômica do Brasil escravista, dois quais cito aqui apenas três:

1. Esses registros permitiram desvelar os largos circuitos de produção para mercados inter-regionais, chamando a atenção para sua articulação com as áreas agro-exportadoras, estas também melhor compreendidas a partir do recurso a essas novas fontes.

2. Possibilitaram também o estudo das unidades produtivas ou empresas (fazendas, casas comerciais, sítios, roças) e de sua envergadura econômica. A o medir os recursos materiais presentes nessas unidades, os historiadores puderam apontar para uma nova compreensão do Brasil escravista. No mundo agrário, ao lado de uns poucos e abastados fazendeiros, existia uma miríade heterogênea de médios e pequenos produtores de alimentos, socialmente muito representativos e que, por vezes, também podiam participar modestamente das culturas de exportação. $\mathrm{E}$ isso se torna tanto mais significativo, quando percebemos que as camadas menos favorecidas tendem a estar sub-representadas nos inventários post mortem (FRAGOSO; PITZER, 1988).

3. Essa mesma fonte tratada por essa mesma metodologia permitiu ainda uma reavaliação do papel decisivo do trabalho escravo, não apenas na grande lavoura, mas também em áreas antes insuspeitadas, como a pecuária do Rio G rande do Sul colonial e dos sertões do Piauí, ou em certas regiões marcadas pela produção agrícola de alimentos, como $M$ inas $\mathrm{G}$ erais na primeira metade do século XIX.

E $m$ minha própria pesquisa, pude estender muitas dessas conclusões para a fronteira sul do Brasil, em meados do século XIX. E ntre outros aspectos, a análise serializada dos dados dos inventários 
mostrou que a principal atividade praticada na região era a pecuária extensiva, com vistas à venda de novilhos para as charqueadas do leste da província, que se conectavam aos mercados das grandes plantations no centro e nordeste brasileiros. Porém, havia também criação de gado muar, vacum e cavalar. A lém disso, a agricultura de alimentos era praticada em diferentes escalas em muitas das unidades produtivas estudadas. M ais importante: ao lado de uma pequena elite de grandes criadores de gado, uma miríade de pequenos e médios produtores estava instalada. $\mathrm{N}$ as grandes estâncias, a mão-de-obra era composta por uma combinação variável de escravos e peões livres. $\mathrm{N}$ as unidades de menor porte, a escravidão também podia se fazer presente, mas o trabalho familiar alcançava protagonismo, conforme nos aproximamos dos estratos menos afortunados (FARINATTI, 2007).

A aplicação de procedimentos seriais na história social na E uropa enfrentou uma situação contraditória na década de 1970. D e um lado, foram, empregados muito além seus campos tradicionais, como na história da leitura ou das crenças religiosas. D e outro, sofreu críticas duras. E stas derivavam tanto da derrocada da confiança nas explicações estruturalistas, que muitas vezes era seu referente implícito, quanto do fato de que muitos daqueles trabalhos começavam a empregar essa metodologia de maneira mecânica e pouco crítica (REVEL, 1998, 2000).

Por tudo que foi dito acima, creio ter ficado claro que não estou entre os que pretendem descartar os procedimentos de quantificação e mesmo de seriação como um dentre vários instrumentos interessantes para as pesquisas em história social. Seus procedimentos podem ser, inclusive, utilizados de forma mais criativa. Porém, é preciso chamar a atenção para alguns pontos importantes levantados nessas críticas. U ma parte deles veio no contexto dos debates estabelecidos pelos historiadores italianos que se lançaram na experiência da microanálise, nas décadas de 1970 e 1980. 
Seguindo volteios, ligando pontos: micro-análise de base nominal

Os historiadores italianos que se inseriram fortemente em um debate sobre as escalas de análise em história, e que ficaram conhecidos como pertencentes à "micro-história", formavam um conjunto heterogêneo de profissionais, nas décadas de 1970 e $1980 .{ }^{2}$ Como traço unificador de seus trabalhos, estava a utilização experimental da redução de escala de análise. E la foi usada para debater problemas como as possibilidades estratégicas dos agentes em meio ao um contexto estruturalmente limitado, ou então os processos de construção e manutenção de identidades culturais, de grupos e hierarquias sociais. N esse contexto, foi importante a reinvenção das fontes e o questionamento às análises feitas "de longe", dentre elas as baseadas em metodologias seriais.

Um dos pontos mais incisivos apontados pela micro-história, na crítica a muitas das análises seriais, era a necessidade de uma atenção maior ao contexto social. Ao renegar a história dos fatos singulares, ao ir em busca de uma história de todos os homens, a história serial optava pelo número, pelo anonimato, pelas médias, frequêencias e modas. Isso trazia vantagens, como a possibilidade de criação de categorias analíticas bem demarcadas e, portanto, suscetíveis de comparação no espaço e no tempo. Porém, se empregado de forma menos crítica, esse procedimento poderia implicar em um isolamento e uma justaposição dos agentes históricos, sem uma atenção analítica para as relações entre eles.

Indo além, uma das principais críticas se dirigia não a todo 0 trabalho de seriação, mas a um procedimento bem específico dentro de parte crescente dos trabalhos seriais à moda francesa: 0 uso naturalizado de classificações sócio-profissionais na análise histórica (REVEL, 2000). N ão se criticava o fato do historiador nomear a um sujeito do passado como camponês, comerciante, artesão, etc. M as sim o fato de se deduzir as escolhas e o comportamento desses 
sujeitos a partir apenas da lógica de funcionamento do estabelecimento rural, da casa comercial ou da oficina. Criticava-se, assim, a criação de um "sujeito médio ou modal" abstrato, que assumiria a forma das características médias ou estatisticamente mais freqüentes dentro da categoria sócio-profissional.

Como apontou Simona Cerutti, o que ocorre aí é um uso restrito da noção de interesse: ao invés de interesses diversos que poderiam orientar as ações dos sujeitos históricos, é apenas o interesse atinente à categoria sócio-profissional que é considerado capaz de imprimir uma direção ao comportamento dos agentes (CE RUTTI, 1998). Acontece que é preciso considerar outros interesses e valores que podiam entrar nesse jogo. As implicações teóricas são claras. A crítica se dirige contra a idéia de um sujeito determinado fortemente por sua posição em uma estrutura sócio-econômica. E m contrapartida, postulava-se uma liberdade limitada que não negava a presença de condicionantes estruturais, mas reservava algum espaço para a escolha e a estratégia, ainda que dentro de um campo de possibilidades limitado e de um horizonte social circunscrito (LEVI, 2000).

Para conseguir divisar com mais clareza esse universo, a receita metodológica era justamente reduzir a escala de análise e passar da abordagem calcada em dados construídos anonimamente para um estudo nominal. Ela deveria permitir encontrar os mesmos sujeitos em diversos documentos e, portanto, em diferentes contextos. A partir daí, poderia-se montar fichas nominais com traços biográficos e reconstruir a configuração de redes de relações sociais. E mpregada em muitas das pesquisas micro-históricas, essa metodologia nominal foi explicitada em um texto do final da década de 1970, que pretendia justamente avaliar as trocas historiográficas entre a França e a I tália (G IN ZBURG e PON I, 1989).

N o Brasil, essas idéias têm exercido influências heterogêneas, difusas em diferentes campos de pesquisa. No que se refere às fontes, a inspiração da micro-história social italiana tem implicado não tanto na descoberta de novos documentos, mas sim em novas formas de usar as fontes, sobretudo nos modos de cruzar diferentes tipos 
de informações. Um exemplo que merece destaque, dentre outros que poderiam ser mencionados, é o de um conjunto de estudos sobre as elites regionais da A mérica Portuguesa. E les têm como grande mérito o fato de situar a importância das relações sociais horizontais e verticais que tais grupos de elite estabeleciam e como essas relações eram vitais para a reprodução de sua posição social. ${ }^{3}$ É uma preocupação que está presente, também, em um trabalho de $\mathrm{G}$ iovanni Levi sobre a comunidade de Felizzano, em que o autor italiano demonstra que não bastava simplesmente adquirir o poder e uma privilegiada posição social: manter a dominação envolvia um reiterado processo de negociação e acomodação com os subalternos (LEVI, 1985). Essa dimensão, até então pouco explorada, abre uma perspectiva importante: a dinâmica das relações das elites regionais com poderes maiores, com seus pares e com os subalternos passam a ser vistas como estruturais na reprodução desses grupos. Tais estudos têm sido possíveis através do cruzamento de fontes muito diversas como genealogias, correspondências administrativas, inventários post mortem, habilitações da 0 rdem de Cristo, listas nominativas e registros de batismo, de modo a mapear trajetórias e relações sociais.

E m minha própria experiência, como foi dito, busquei montar um quadro de referência com bases seriais e, depois, recompor trajetórias e relações a partir de um estudo nominal. Por razões práticas, esse estudo intensivo precisava se restringir a um conjunto de sujeitos (escolhi a elite econômica), através de um procedimento de micro-análise. E sse estudo deveria servir para ratificar, refinar ou retificar as conclusões e os próprios termos de alguns momentos da análise serial, além de trazer elementos novos, possíveis de serem visualizados em razão da redução da escala de análise. Um dos pontos desenvolvidos assentava-se exatamente na construção de categorias sócio-profissionais e no debate sobre sua pertinência para a análise dos grupos sociais existentes na sociedade da fronteira meridional do Brasil, no século XIX. 
U ma análise ocupacional a partir do estudo das avaliações de bens e das partilhas dos inventários me levaria a dividir os inventariados da elite econômica tendo como critério as suas ocupações principais: estancieiros, estancieiros-militares e comerciantes. D e fato, essa especialização existia. Porém, ela estava longe de ser absoluta. A o longo da vida, os mesmos sujeitos desempenhavam atividades diferentes, por vezes ao mesmo tempo. Ainda que tivessem uma atividade predominante, ela é relativizada quando rompemos 0 isolamento dos agentes. A o reconstruir as relações familiares desses sujeitos a partir do banco de dados nominal, descobri que as configurações familiares envolviam pessoas que atuavam nessas três áreas. Assim, ainda que o Sr. Manoel José de Carvalho, dono da maior fortuna da amostra, fosse um grande estancieiro que não tinha cargos militares e não exercia o comércio, ele tinha um genro comerciante, outro genro capitão da guarda nacional e filho de um Brigadeiro do Exército, e uma nora que era filha de um Coronel da G uarda $\mathrm{N}$ acional, que fora Comandante da Fronteira (FARIN ATTI, 2007).

$N$ aquela realidade pré-industrial, o comércio, a criação de gado e a presença em altos cargos militares devem ser vistos não como matrizes de categorias ocupacionais homogêneas, esim como campos de atuação que os agentes procuravam acessar por si ou por seus parentes. O bviamente, isso implica em um estudo mais detido sobre os significados dos laços familiares naquele contexto, que não cabe nessa exposição.

\section{Conflitos, relações ea produção social dos documentos}

0 utro ponto importante da crítica feita à forma como muitos estudos seriais vinham sendo conduzidos ataca a desatenção para com o caráter conflituoso e propriamente social da produção dos documentos utilizados. $N$ inguém pode acusar os historiadores seriais de ingenuidade quanto à consciência de que o pesquisador produz suas próprias fontes. A o contrário, um dos grandes méritos 
dos trabal hos seriais reside na explicitação das escolhas, recortes e critérios empregados no manejo dos documentos. Isso não deve surpreender, dado que as séries produzidas pelo historiador se distanciam claramente dos documentos utilizados para construí-las, ainda que sempre estejam referenciadas neles. $N$ esse sentido, na esteira da tradição dos A nnales, aqueles historiadores tinham claro que um documento não é uma evidência em si e exige a mediação do pesquisador - de seus métodos, problemas e hipóteses - para se tornar utilizável como uma fonte histórica. Contudo, nem sempre essas preocupações se traduziram na percepção de que o documento utilizado fora produzido em meio a um embate de tensões e relações sociais diversas. $\mathrm{O}$ u, se havia tais percepções, ela não era tomada como um fator a ser trazido para a análise.

$\mathrm{H}$ á mais de duas décadas, já se afirmou que os processos criminais constituíam uma encruzilhada de muitas lutas (CHALHOUB, 2001). Sem dúvida, essa é uma das fontes que mais tem sido explorada a partir das tensões que presidiram a própria forma como foi construída enquanto documento. D epois disso, Márcia M otta levou essas idéias para o campo da história agrária e das fontes serializáveis, ao mostrar que os registros paroquiais de terra, elaborados da aplicação da Lei de Terras, na década de 1850, não podiam ser vistos como um retrato da estrutura agrária de uma paróquia em um dado momento. Como demonstrou Motta, as declarações feitas ali, que não tinham nenhuma necessidade prova, expressavam sim intenções de domínio, muitas vezes contraditórias entre si, e eram sim fontes pertinentes para 0 estudo dos conflitos em torno do direito à terra (MOTTA, 1998). ${ }^{4}$

E ssa é uma abordagem que pode e deve ser estendida, também, a outras fontes que, a uma primeira vista, sugeririam um tratamento a partir da seriação. Podemos encarar de modo semelhante, por exemplo, as informações presentes nas listas de qualificação para as eleições ou para o serviço na G uarda N acional, no B rasil monárquico. A pesar de trazerem informações como a profissão ea renda dos qualificados, devemos manter algum ceticismo quanto à possibilidade 
de, a partir delas, montar um quadro confiável de categorias ocupacionais ou da concentração de renda em determinado município. $\mathrm{E}$ isso não apenas porque as camadas mais pobres da população escapavam a essas fontes, mas também porque as atribuições de renda eram muito aproximativas e, sobretudo, porque a qualificação era um processo no qual os interesses e as relações sociais podiam ter grande influência.

Isso não quer dizer que devemos desistir delas como fontes para o estudo da história social. E $\mathrm{m}$ primeiro lugar, porque, quando aceitamos seu caráter incompleto, podemos nos valer daquelas informações como indícios que podem ser corrigidos na comparação com outras fontes ou em estudos futuros. Se é inadequado construir um quadro da hierarquia social, econômica ou sócio-profissional a partir dessas fontes e confiar nele, parece-me que é valido montar tal quadro, em caráter experimental e desconfiar dele. 0 u seja, utilizá-lo como um referencial hipotético e realizar cruzamentos com outras fontes. N esse caso, as semelhanças encontradas podem ir conferindo alguma confiabilidade ao quadro traçado, enquanto que as discrepâncias podem ensinar muito sobre a especificidade da produção social daquele documento.

E $m$ segundo lugar, os interesses, as relações de reciprocidade vertical e horizontal, as tensões e conflitos que podiam influenciar na construção daquelas listagens devem, eles mesmos, tornar-se objeto de estudo. N esse sentido, considero muito interessante a possibilidade de estudar documentos como as listas de qualificação de votantes e da G uarda N acional de uma forma micro-analítica. I sso significa tomar os sujeitos listados ali e buscar informações sobre eles em um banco nominal construído a partir de fontes diversas (registros de batismo, casamento, escrituras públicas, processos criminais, etc.). Assim, é possível conhecer as relações sociais desses sujeitos entre si e com outros agentes. E ssas informações, por sua vez, servem para estudar de modo contextual os fatores que influenciavam os processos de produção social do serviço na $G$ uarda $\mathrm{N}$ acional e da qualificação eleitoral. 
O s inventários post mortem, ainda que também abrigassem fraudes, são mais confiáveis do que as listas de qualificação no que tange à possibilidade de analisar patrimônios, de perceber a concentração de fortunas e recursos porque envolvem interesses contraditórios dos herdeiros que, em tese, exerceriam uma fiscalização sobre as irregularidades do processo. Contudo, também é possível ganhar quando associamos ao estudo serializado, uma análise da produção social do documento, realizada de forma micro-analítica.

Ao estudar as grandes estâncias da fronteira meridional do Brasil procedi, primeiramente, a uma descrição do patrimônio de cada unidade produtiva, consubstanciada nas avaliações de bens presentes nos inventários post mortem (FARIN ATTI, 2007). N esses processos, aparece cada estância com seus animais, seus instrumentos de trabalho, suas construções, seus trabalhadores escravizados. Porém, elementos novos advieram do estudo de alguns casos a partir de outras partes do inventário como a alimpação da partilha, as declarações do inventariante, procurações e correspondências anexas ao processo, bem como de outros documentos como escrituras públicas e ações de cobrança de dívidas. 0 cruzamento dessas fontes no estudo de algumas famílias da elite agrária mostrou que, muitas vezes, unidades produtivas que aparecem de modo estanque nos inventários post mortem, estavam, na verdade, muito integradas. O s filhos criavam gado nos campos dos pais enquanto solteiros e, alguns deles, mesmo depois de casados. Com muita regularidade, membros da família vendiam gado, remuneravam peões e utilizavam o trabalho de escravos pertencentes a seus pais, filhos, cunhados, genros ou irmãos. E ssa circulação de recursos entre os núcleos familiares escapa ao pesquisador quando este analisa apenas as unidades produtivas descritas nas avaliações dos inventários e que, por seu critério baseado na propriedade jurídica dos bens, apresenta de modo estanque elementos que estavam em contínua relação.

Para finalizar, gostaria de apontar para o fato de que os procedimentos micro-analíticos também guardam suas ciladas. A meu ver, um dos pontos que exige cuidado é a naturalização da efetividade 
das relações sociais sugeridas pelo banco de dados. Se é verdade que, em uma pesquisa serial, um inventário post mortem pode sugerir uma disposição exageradamente ordenada da unidade produtiva, ou uma posição demasiadamente estanque dos sujeitos sociais; também é verdade que a existência de uma ligação familiar, comercial ou política entre dois sujeitos, por si só, não diz muito sobre a natureza dos compromissos e da identidade que eles mantinham entre si. A qui, são grandes as tentações oferecidas pela beleza da simetria descoberta pelo historiador quando encontra nas fontes uma relação entre os sujeitos pesquisados. É necessário cuidado para evitar uma leitura apressada. É preciso indagar sobre as características específicas dessas relações: afinal, o que significava mesmo, naquele contexto, ser cunhado, compadre, credor ou companheiro de armas? E $m$ que condições essas relações se faziam efetivas e que compromissos eram capazes de gerar?

\section{Considerações Finais}

Como deve ter restado claro, não estou entre aqueles que consideram incompatíveis, a priori, a combinação de procedimentos seriais e micro-analíticos. A s contradições aparecem, isso sim, quando se procura simplificar a análise da atuação de sujeitos sociais tomando como base apenas sua principal atividade sócio-profissional ou então quando se deixa de lado as peculiaridades sociais da própria construção do documento com o qual se está trabalhando. N esse ponto, a crítica feita a partir dos trabalhos micro-históricos é pertinente e inspiradora. Contudo, ela não ataca o fato de que os proce dimentos seriais continuam importantes para diversos estudos, inclusive os que se baseiam principalmente em inventários post mortem, como a análise da composição de patrimônios, de concentração de fortunas e de recursos produtivos.

Tanto no caso de estudos seriais como micro-analíticos, não me parece que o problema esteja no uso desta ou daquela fonte, 
nem no emprego de determinado procedimento metodológico, em detrimento de outra ou da combinação de ambas, mas sim em sua naturalização e na recusa em se refletir sobre sua pertinência, compatibilidades e implicações teóricas.

Construction of series and micro-analysis: notes on the treatment of sources for the social history

Abstract: This article makes a reflection concerning the treatment of so urces in social history. Thefocus is on the sources that can beapproached starting from two types of methodologies. In the first place, the construction of series based on anonyms and quantitativedata. Secondly is the micro-analysis, which aims to rebuild paths and social relationships starting from thestudied agents' names. Starting from a specific experience of research, reflections aremadeabout the research possibilities created by those sources, the compatibility of both methodologies and the pertinence of their use.

Keywords: H istorical sources. Social history. Serial history. M icro-history. M ethodology

\section{$\mathrm{N}$ otas}

1É o caso, por exemplo, de: M artins (1983); M attos (1987); A Imeida (1994); Z arth (1997, 2002); Faria (1998); Schwartz (1999); Barickman (2003); Sampaio (2003); 0 sório (2007).

2 Para uma análise mais aprofundada so bre a micro-história italiana, ver: L evi (1992); Revel (1998); Lima (2006).

${ }^{3}$ E ntre outros: F ragoso (2000, 2002, 2003); A Imeida (2003); Batista (2004); H ameister (2006); M artins (2007); G il (2007); 0 sório (2007).

${ }^{4} \mathrm{O}$ mesmo procedimento foi utilizado, com sucesso, em trabalhos posteriores. Ver: Christilino (2004); G arcia (2005).

\section{Referências}

A L M E ID A, Carla. A Iterações nas unidades de produçōes mineiras: M ariana, 1750-1850. N iterói: PPG H -UFF, 1994. (D issertação de M estrado), $220 f$.

ALMEIDA, Carla. H omens R icos, H omens B ons: produção e hierarquização social em M inas C olonial (1750-1822). N iterói: PPG H -UFF, 2001, (Tese de doutorado), $302 f$.

BARICK MAN, Bert. U m contraponto baiano: açúcar, fumo, mandioca e escravidão no Recôncavo (1780-1860). Rio de Janeiro: Civilização Brasileira, 2003.

Anos 90, Porto Alegre, v. 15 n. 28, p. 57-72, dez. 2008 
Luís Augusto Farinatti

BATISTA, L uciana M arinho. M uito A lém dos Seringais: $E$ lites, Fortunas eH ierarquias no G rão-Pará, c 1850 - c1870. Rio deJaneiro: UFRJ, 2004, (D issertação deM estrado), $283 f$.

CE RUTTI, Simona. Processo e Experiência: indivíduos, grupos e identidades em Turim no século XVII. I n: RE VE L, Jacques (O rg.). Jogos deE scalas: a ex periência da micr oanálise. Rio de Janeiro: F undação G etúlio Vargas E ditora, 1998, p. 173-201.

CH A LH O U B, Sidney. T rabalho, L ar eB otequim: 0 cotidiano dos trabalhadores do R io de Janéro na BelleÉ poque 2. ed. Campinas: E ditora U nicamp, 2001.

FRAG O SO, João. A fogando em N omes: temas eexperiências na históriaeconômica. Topói, R evista do Programa dePós-G raduação em $H$ istória Social. Rio de Janeiro: UFRJ, n. 5, p. 41-70, 2002.

FRAG O SO, João. H omens deG rossa A ventura: acumulação ehierarquia na praça mercantil do R io dejaneiro (1790-1830), 2. ed., Rio de Janeiro: Civilização Brasileira, 1998.

GARCIA , G raciela. 0 domínio da terra: conflitos eestrutura agrárianaCampanhariograndense oitocentista. Porto A legre, 2005. D issertação (M estrado em H istória) Programa de Pós-G raduação em História, Universidade Federal do Rio G rande do Sul, $191 f$.

GIL, Tiago L uís. Infiêis T ransgressores: os contrabandistas nas fronteras de $R$ io $G$ rande e de Rio Pardo (1760-1810). Rio de Janeiro: A rquivo N acional, 2007.

GIN ZBURG, Carlo ePO N I, Carlo. 0 N omee o Como: trocadesigual no mercado historiográfico. In: A M icro-história e outros ensaios. Lisboa: D ifel. Rio de Janeiro: Bertrand Brasil, 1989, p. 169-178.

G OUBERT, Pierre. Cent M ille Provinciaux au X V II siède - B ouvais et le B ouvaisis de 1600 a 1730. Paris: Flamarion, 1968.

LA A R R U SSE , E rnest. F lutuaciones económicas y historia sodal. M adrid: Tecnos, 1962.

LAD URIE, E mmanuel Le Roy. Les Paysans deL anguedoc. Paris: Sevpen, 1966.

LEVI, G iovanni. Sobrea micro-história. In: BURK E, Peter (O rg.) A E scrita da H istória. São Paulo: UN E SP, 1992, p. 133-161.

LEVI, G iovanni. A H erança Imaterial: trajetória de um ex orcista no Piemonte do século X V II. Rio de aneiro: Civilização Brasileira, 2000.

LEVI, G iovanni. Centro ePeriferia deuno Stato A ssoluto. Turim: Rosemberg \& Sieller, 1985.

LI M A, H enrique E spada. A micro-história italiana - escalas, indícios e singularidades. Rio deJ aneiro: Civilização Brasileira, 2006.

LI N H A RE S, Maria Yedda; SI LVA, Francisco Carlos T. H istória da A gricultura B rasileira, combates e controvérsias. São Paulo: B rasiliense, 1981.

Anos 90, Porto Alegre, v. 15 n. 28, p. 57-72, dez. 2008 
Construção de séries e micro-análise...

MARTIN S, M ariaFernanda Vieira. A V etha A rtedeG overnar. U m estudo sobrepolítica e elites a partir do C onselho deE stado (1842-1889). Rio de Janeiro: A rquivo N acional, 2007.

MARTIN S, Roberto Borges. M inas G erais - século X IX : tráfico e apego à escravidão numa economia não exportadora. E studos E conômicos, v. 13, n. 1, p.181-209 . São Paulo: Fipe/ USP, 1983.

M ATT OS, H ebe M aria. A o Sul da H istória: lavradores pobres na crise do trabal ho escravo. S São Paulo: Brasiliense, 1987.

M O TTA , M árcia M .M . N as F ronteiras do Poder: conflito edireito à terra no B rasil do século X IX . Rio de Janeiro: A rquivo Público do Rio de Janeiro/ Vício de L eitura, 1998.

O SÓ RIO, Helen. 0 Império Português no Sul da A mérica: estancieiros, lavradores e comerciantes. Porto A legre: E ditora da UFRG S, 2007.

REVE L, Jacques. A história ao rés do chão. I L LEVI, G iovanni. A H erança Imaterial: trajetória deum ex orcista no P iemontedo século X V II. Rio de Janeiro: Civilização Brasileira, 2000, p. 7-37.

REVE L, Jacques. M icroanálise e construção do social. I n: REVE L, Jacques (0 rg.). J ogos de escalas - A experiência da microanálise. Rio de Janeiro: FG V, 1998, p. 15-38.

SA M PAI O, A ntonio Carlos Jucá de. N a encruzilhada do Império: hierarquias sociais e conjunturas econômicas no R io de Janeiro (c. 1650- c.1750). Rio de Janeiro, A rquivo N acional, 2003.

SCH WARTZ, Stuart. Segredos internos: engenhos e escravos na sociedade col onial (15501835). São Paulo: Cia. das Letras, 1999.

ZARTH , Paulo A fonso. H istória A grária do P lanalto G aúcho. I juí: E ditora da U N IJUÍ, 1997.

D o A rcaico ao M oderno: 0 R io G rande do Sul agrário do século X IX . I juí: E- ditoraUN IJUÍ, 2002.

Recebido em 24/ 09/2008

A provado em 04/ 11/ 2008

Anos 90, Porto Alegre, v. 15 n. 28, p. 57-72, dez. 2008 